\title{
Early intervention in psoriasis and immune- mediated inflammatory diseases: A hypothesis paper
}

G. Girolomoni, C. E. M. Griffiths, J. Krueger, F. O. Nestle, J-F. Nicolas, J. C. Prinz, L. Puig, M. Ståhle, P. C. M. van de Kerkhof, M. Allez, P. Emery \& C. Paul

To cite this article: G. Girolomoni, C. E. M. Griffiths, J. Krueger, F. O. Nestle, J-F. Nicolas, J. C. Prinz, L. Puig, M. Ståhle, P. C. M. van de Kerkhof, M. Allez, P. Emery \& C. Paul (2015) Early intervention in psoriasis and immune-mediated inflammatory diseases: A hypothesis paper, Journal of Dermatological Treatment, 26:2, 103-112, DOI: 10.3109/09546634.2014.880396

To link to this article: https://doi.org/10.3109/09546634.2014.880396

ə (C) 2015 The Author(s). Published by Taylor \& Francis.

Submit your article to this journal \lceil

View related articles $\sqsubset$

Citing articles: 10 View citing articles $\sqsubset$
央 Published online: 19 Feb 2014.

III Article views: 3685

View Crossmark data ¿ 


\title{
Early intervention in psoriasis and immune-mediated inflammatory diseases: A hypothesis paper
}

\author{
G. Girolomoni ${ }^{1}$, C. E. M. Griffiths ${ }^{2}$, J. Krueger ${ }^{3}$, F. O. Nestle ${ }^{4}$, J-F. Nicolas ${ }^{5}$, J. C. Prinz ${ }^{6}$, L. Puig ${ }^{7}$, M. Ståhle ${ }^{8}$, \\ P. C. M. van de Kerkhof ${ }^{9}$, M. Allez ${ }^{10}$, P. Emery ${ }^{11,12}$, and C. Paul ${ }^{13}$
}

\begin{abstract}
${ }^{1}$ Department of Medicine, Section of Dermatology and Venereology, University of Verona, Verona, Italy, ${ }^{2}$ Dermatology Centre, Salford Royal Hospital, The University of Manchester, Manchester Academic Health Science Centre, Manchester, UK, ${ }^{3}$ Laboratory of Investigative Dermatology, The Rockefeller University, New York, NY, USA, ${ }^{4}$ St. John's Institute of Dermatology, King's College London School of Medicine, Division of Genetics and Molecular Medicine, Guy's Hospital, London, UK, ${ }^{5}$ Department of Allergology \& Clinical Immunology, UFR Lyon-SUd, INSERM U851, IFR 128, University of Lyon, France, ${ }^{6}$ Department of Dermatology, University of Munich, Munich, Germany, ${ }^{7}$ Department of Dermatology, Hospital de la Santa Creu i Sant Pau, Universitat Autònoma de Barcelona, Barcelona, Spain, ${ }^{8}$ Unit of Dermatology, Department of Medicine, Karolinska Institutet, Stockholm, Sweden, ${ }^{9}$ Department of Dermatology, Radboud University Nijmegen Medical Centre, Nijmegen, The Netherlands, ${ }^{10}$ Department of Gastroenterology, Saint-Louis Hospital, APHP, Université Denis Diderot Paris 7, Paris, France, ${ }^{11}$ Leeds Institute of Rheumatic and Musculoskeletal Medicine, University of Leeds, Chapel Allerton Hospital, Leeds, UK, ${ }^{12}$ NIHR Leeds Musculoskeletal Biomedical Research Unit, Leeds Teaching Hospitals NHS Trust, Leeds, UK, and ${ }^{13}$ Paul Sabatier University and Dermatology Department, Hôpital Larrey, Toulouse, France
\end{abstract}

\begin{abstract}
Psoriasis is an immune-mediated inflammatory disease (IMID) which may have a major impact on a patient's life, especially when the disease is moderate to severe. There is evidence that treatment of psoriasis during the first years is conservative and frequently based on topical agents which rarely clear lesions. Treatment with systemic agents including biologics is often undertaken only when topical agents have proved unsuitable, even in patients with moderate to severe disease. However, there is evidence that in other IMIDs (rheumatoid arthritis and Crohn's disease), targeted systemic treatment given early in the treatment pathway may improve long-term patient outcomes. We hypothesize that a patient-centered therapeutic approach, undertaken early in the psoriasis treatment pathway ("early intervention") with the goal of complete clearance, may improve control of cutaneous symptoms and may also modify disease course and burden. Critical points to address when designing an early intervention study would include: the definition of psoriasis disease activity; patient selection; intervention selection; and dosing strategies.
\end{abstract}

\section{Introduction}

Psoriasis is a common condition, with a prevalence of $2 \%$ in the USA and between $1.6 \%$ and $4.8 \%$ in Europe $(1,2)$. It is associated with significant impact on all aspects of patients' lives (3). In some patients, the cumulative effect of this impact perpetuates social disconnection and stigmatization (4). Patients with severe psoriasis have been shown to have a greater probability of low income and a lower probability of working as a result of their condition, compared to those with mild disease (5). The disease has also been associated with significant reductions in health-related quality of life (HRQoL), particularly in patients with severe disease and in younger patients $(6,7)$. The social impact of psoriasis has been linked to changes in cognitive processing of facial expressions of disgust encountered by psoriasis patients (8). Psoriasis has also

This is an Open Access article distributed under the terms of the Creative Commons Attribution License (http://creativecommons.org/Licenses/by/4.0/), which permits unrestricted use, distribution, and reproduction in any medium, provided the original work is properly cited.

Correspondence: Carle Paul, Paul Sabatier University and Dermatology Department, Hôpital Larrey, 24 Chemin de Pouvourville, 31059 Toulouse Cedex 9, France. Tel: +33 567 778140. Fax: +33 567 778142. E-mail: paul.c@chu-toulouse.fr

\author{
Keywords \\ Comorbidities, early intervention, \\ management, pathophysiology, psoriasis
}

\section{History}

Received 24 December 2013

Accepted 28 December 2013

Published online 12 February 2014 been reported to be associated with metabolic disorders including obesity, non-alcoholic fatty liver disease (NAFLD), dyslipidaemia, and diabetes, as well as disorders that confer an unfavorable cardiovascular risk profile and higher mortality rates. These risks may be directly related to disease severity and duration, although the strength of the association varies across studies (9-11).

Psoriasis is an immune-mediated inflammatory disease (IMID) affecting the skin which is associated with psoriatic arthritis in about one-third of patients $(12,13)$. Other IMIDs include ankylosing spondylitis (AS), rheumatoid arthritis (RA), and Crohn's disease (CD). The distinguishing feature of IMIDs is that their underlying pathology is caused by the dysfunction of the immune system, resulting in chronic and damaging inflammation. As such, the treatment of IMIDs overlaps, specifically in the management of severe disease. A developing body of data suggests that more aggressive therapeutic intervention earlier in the treatment pathway in RA and CD may provide high levels of efficacy and tolerability, with improved long-term patient outcomes and disease prognosis (14-26). No such early intervention studies have been carried out in psoriasis to date, although the possibility of modifying the course of the disease has been proposed $(27,28)$. In contrast, there is evidence of a delay in using systemic agents and biologics in moderate-tosevere psoriasis which exceeds 3 years in $50 \%$ of patients (29). 


\section{The pathophysiology of psoriasis}

\section{There is a strong genetic basis for psoriasis which has features in common with other IMIDs}

Studies of psoriasis prevalence in families and concordance rates in twins indicate a strong genetic component, which is in line with other IMIDs. Farber and colleagues (30) first demonstrated this with the finding that among 61 pairs of twins, the risk of psoriasis was 2-3 times higher in monozygotic siblings, compared with dizygotic siblings. At least, nine chromosomal loci with a significant linkage to disease development have since been identified and have been named psoriasis susceptibility (PSORS) 1-9 (31).

Genome-wide scans have identified additional genes or gene loci associated with psoriasis. Most of the genes so far identified have to do with innate and adaptive immunity (32). These include genes encoding the interleukin-23 receptor (IL23R), zinc-finger protein 313 (ZNF313), CDKAL1, PTPN22, the IL-4-IL-13 gene cluster and more recently, ERAP1 and late cornified envelope (LCE) (33-60). The association of psoriasis with such genes has raised a great deal of interest for two reasons. First, many of these genes have a role in controlling and modifying the immune response, which is the key driver of psoriasis and other IMIDs. For example, the IL-12, IL-23, and IL-4-IL-13 gene cluster products are associated with T-helper cell differentiation, cellmediated immune responses, and the development of some autoimmune diseases $(33,34,36)$. Second, many of the genes associated with psoriasis overlap those associated with other IMIDs. CDKAL1, for example, is a known risk factor for the development of CD $(35,59)$.

\section{Subclinical inflammation in healed plaques following treatment of psoriasis may trigger disease recurrence}

Gene expression patterns in the involved skin of individuals with psoriasis are significantly different from expression patterns in uninvolved, clinically normal skin. Intriguingly, gene expression studies in patients treated with etanercept suggest that resolution of the epidermal reaction in psoriasis following successful systemic treatment is not accompanied by full resolution of the inflammation, as defined by expression of key cytokines and chemokines $(61,62)$. This phenomenon of residual genomic expression has been tentatively characterized as a "molecular scar", and may be analogous to the non-reversible damage associated with progression of other IMIDs, such as RA. It may result in subclinical inflammation responsible for early disease recurrence.

The observation that psoriasis is associated with polymorphism in immunomodulating genes suggests that the basis of the disease is a selective immune dysfunction. Hence, an effective treatment strategy for psoriasis should target this dysfunction and should take into account the genetic basis that persists despite clinically effective therapy. In addition, because many of the genes associated with psoriasis are also risk factors for other IMIDs, systemic treatment approaches that are effective in one disease may have a bearing on the clinical management of another.

\section{Plaque development and the immune response in psoriasis}

The development of plaques of psoriasis is a multistage process that involves overt activation of the innate and adaptive immune systems (63-68). According to current concepts, the release of endogenous DNA in combination with the anti-microbial protein LL37 is detected by plasmacytoid dendritic cells (DCs), resulting in the production of interferon- $\alpha$ (IFN $\alpha)(69,70)$. Recruitment of plasmacytoid DCs in psoriatic skin is strictly dependent on the chemerin/ChemR23 axis, and is temporally active during psoriatic plaque development (71). Pro-chemerin is produced primarily not only by dermal fibroblasts, but also by mast cells and endothelial cells. Once secreted, it is activated by enzymes produced by neutrophils, which extravasate in early psoriasis lesions. Other cells of the innate immune system that respond include keratinocytes, which release IL- $1 \beta$, IL-6, tumor necrosis factor- $\alpha$ (TNF $\alpha)$ and various chemokines, and macrophages that secrete $\mathrm{TNF} \alpha$. This induces recruitment and activation of myeloid DCs.

Myeloid DCs induce the antigen-specific activation and differentiation of naïve T-cells into type 17 or type 1 T-helper cells (Th17 or Th1) by secreting IL-12 or IL-23, respectively. These effector T-cells accumulate in the skin and promote plaque formation through the release of a cocktail of pro-inflammatory cytokines. Th17 cells secrete IL-17A, IL-17F, and IL-22, while Th1 cells release TNF $\alpha$ and IFN $\gamma$. These cytokines act directly on keratinocytes resulting in hyperplasia and the production of additional cytokines and chemokines (e.g. IL-1 $\beta$, IL-6, TNF $\alpha$, CXCL8, and CCL20). The release of inflammatory mediators by keratinocytes has several effects: the attraction of additional immune cells (e.g. macrophages, and neutrophils), the production of collagen and proteoglycans by fibroblasts, the activation and perpetuation of an inflammatory response, and the propagation of an adaptive immune response $(11,65)$. Hence, the outcomes of stimulation of a small region of psoriasis-predisposed skin results in an immune reaction that can lead to the development of lesions at local and distant body sites, as well as systemic effects.

\section{The relationship between psoriasis and other IMIDs}

Many of the loci associated with psoriasis are also associated with other IMIDs. Furthermore, the pathophysiological basis of IMIDs has, in recent years, been shown to involve the activation of an inflammatory response and T-cells via DCs (72). It is, therefore, unsurprising that patients with IMIDs frequently suffer from related conditions. Psoriatic arthritis (PsA) - an erosive, polyarticular, joint damaging disease that can progress to the loss of function - occurs in 10-34\% of individuals with psoriasis, compared with a rate of $0.04-1.2 \%$ in unaffected individuals $(13,73,74)$. Prevalence of psoriasis has been shown to be significantly higher in patients with inflammatory bowel disease (CD or ulcerative colitis), compared with controls. Psoriasis prevalence was also higher in first-degree relatives of these patients (75). Finally, there appears to be an increased incidence of PsA in patients with CD, and the latter disease shows an association with a coding variant of the IL23R gene (76).

Although the localized inflammatory response leads to the defining symptoms of IMIDs (skin lesions in psoriasis, inflammation of the gastrointestinal tract in $\mathrm{CD}$, and inflammation of the joints in RA), activation of the adaptive immune system is not so organ-specific. Indeed, the observation that patients with psoriasis are more likely to suffer from another IMID suggests that psoriasis is a systemic inflammatory disease, or has systemic inflammatory consequences (72).

Research has since focused on the comorbidities associated with psoriasis. Patients with severe psoriasis may have a higher risk of developing ischemic heart disease, cerebrovascular disease, peripheral vascular disease, and NAFLD compared with controls (77-85). Patients with psoriasis are also more likely to have risk factors for vascular disease (e.g. diabetes mellitus, hypertension, and dyslipidaemia) than unaffected individuals, although the results of epidemiological studies are heterogeneous. There is a significant association between psoriasis and metabolic syndrome $(1,9)$, a strong predictor of diabetes and cardiovascular disease, although the strength of the association varies across studies $(10,85,86)$. Psoriasis is associated with an increased risk of cardiovascular disease (myocardial infarction and stroke) and 
mortality. However, there is still controversy about the specific contributing role of cardiovascular risk factors, including hypertension, smoking and hypercholesterolemia, versus the specific role of psoriasis-related inflammation (13). It is still uncertain whether psoriasis per se is an independent cardiovascular risk factor $(86,87)$. The recent finding that patients with psoriasis show an overexpression in lesional skin of mRNA from genes linked to cardiovascular risk (e.g. inflammatory mediators and renin), corresponding to increased levels of the relevant proteins in the serum, is highly suggestive in this regard (88).

\section{Early intervention: towards a new treatment paradigm for psoriasis}

Psoriasis affects both physical and psychological aspects of a patient's life culminating in self-perpetuating social disconnection $(4,89)$. A cardinal aim of treatment in psoriasis is to ameliorate the course of the disease, to prevent relapses, and to improve overall prognosis by reducing severity. Unfortunately epidemiological studies indicate that most physicians still use a conservative approach in psoriasis treatment. This results in long delay for patients to achieve a high level of clearance. A more aggressive approach with systemic agents or biologicals used earlier in the treatment paradigm with the goal of complete clearance may change the natural history of the disease, help more patients to achieve long-term remission, and improve long-term outcomes $(26,27)$. One initiative to be explored further is the concept of multidimensional patient education, which was shown to improve patient outcome in a single-centre study (90).

This hypothesis has parallels in other clinical disciplines. A clinical study in which patients with RA were treated with the anti-TNF infliximab, found a markedly reduced risk of myocardial infarction as early as at 6 months in responding patients, with improvements in endothelial function after treatment $(91,92)$. In psoriasis, it remains to be determined whether the higher risk of cardiovascular disease is related to systemic inflammation, to traditional risk factors such as smoking, obesity and a sedentary lifestyle, or to genetic factors $(82,83)$. Nevertheless, early and long-term control of psoriasis inflammation alongside appropriate management of cardiovascular risk factors may help to improve patient outcomes. Since the burden of psoriasis and the relative risk for myocardial infarction appear to be much higher in younger patients (78), patients with early-onset, moderateto-severe psoriasis may be the population most likely to benefit from early intervention. The choice of the most suitable therapeutic agents to initiate early intervention treatment requires careful discussion (93).

Even though in most cases the clinical activity of psoriasis does not lead to irreversible or progressive structural skin damage, functional impairment can be very significant. The overall impact on a patient's life is related to the severity and duration of active disease, taking into account not only the extent but also the visibility of the lesions, the functional impairment associated with palmoplantar, genital or nail disease, the presence of associated arthritis, the frequency of relapses, and the need for systemic treatment. These considerations suggest that a new treatment paradigm may be required for psoriasis, especially for young patients with severe disease who may carry a high risk of stigmatization and social exclusion.

\section{Early intervention in psoriasis: lessons from other IMIDs}

\section{Crohn's disease}

The clinical course of CD has some features in common with the course of psoriasis. It is a disease characterized by unpredictable phases of activity and quiescence. In $\mathrm{CD}$, chronic inflammation can lead to the development of complications (such as strictures, fistulae, and abscesses) and definitive tissue damage. A minority of CD patients present uncomplicated courses in which phases of activity alternate with phases of complete remission. In most patients, chronic inflammation can induce definitive damage even in phases of symptomatic remission (94). However, there is an increased early usage of immunosuppressants and anti-TNF agents (95).

Anti-TNF therapies, with or without immunosuppressants, have been demonstrated to alter the course of disease. Notably, anti-TNFs can induce mucosal healing and reduce CD-related hospitalizations and surgeries (96-98). Achievement of mucosal healing is associated with a reduced rate of relapses (99). In clinical practice, the agents are often used late in the disease course, frequently in patients who have already developed definitive tissue damage. The use of anti-TNF treatments early in the course of CD has shown a high efficacy in the induction of steroid-free clinical remission and endoscopic remission defined as complete mucosal healing in patients with poor prognosis (Table 1) $(22,23,99)$. The challenge is now to identify predictors of poor outcome, which would allow early, aggressive intervention in subgroups of patients with poor prognosis.

\section{Rheumatoid arthritis}

The treatment of RA has changed significantly over the past decade. This is a result of studies demonstrating that early, aggressive therapy can achieve rapid disease control and may prevent long-term radiographic progression and irreversible joint damage. Treatment strategy trials have demonstrated that in the majority of patients with RA, the following approach is the most beneficial: goal-driven, dynamic treatment towards tight control of disease activity, including early introduction of one or more effective disease-modifying antirheumatic drugs (DMARDs) in combination with prednisone or anti-TNF, which includes tapering of the medication if remission or low disease activity is achieved (100). Currently, patients with RA tend to be treated first-line with a DMARD such as methotrexate (MTX) $(15,16)$. Biologics are licensed for patients who show inadequate response or intolerance to DMARDs, and also for patients with severe, active, and progressive RA not previously treated with DMARDs (15). Studies have shown that the early use of biologics in combination with MTX increases rates of remission, improves symptoms and halts joint damage (Table 2) (14-22,101). In the BeST study, after an earlier improvement in functional ability and quality of life with initial combination therapy, clinical outcomes were comparable across the groups from 1 year onwards and stable up to 5 years. The initial combination groups showed less joint damage in year 1 . In years 2-5, annual progression was comparable across the groups. After 5 years, initial combination therapy resulted in significantly less joint damage progression, reflecting the earlier clinical response (102). Patients treated with MTX alone, even when achieving remission, will demonstrate progression of damage predicted by subclinical synovitis (103). Long-term data of early remission induction are now available showing long-term benefits (104). For patients with RA, clinical features are insufficient to give an accurate picture of the disease state (105), and joint damage has been shown to progress despite a sustained clinical remission in early rheumatoid arthritis patients after etanercept interruption (106). A similar approach has been undertaken in AS with patients in the prodromal period being treated with infliximab, with evidence of early response and some long-term benefit (107). This parallels the situation in psoriasis where there seems to be a need to "reset" the disease, as shown at various levels. 
Table 1. Summary of key studies assessing early intervention with biologics in Crohn's disease (CD).

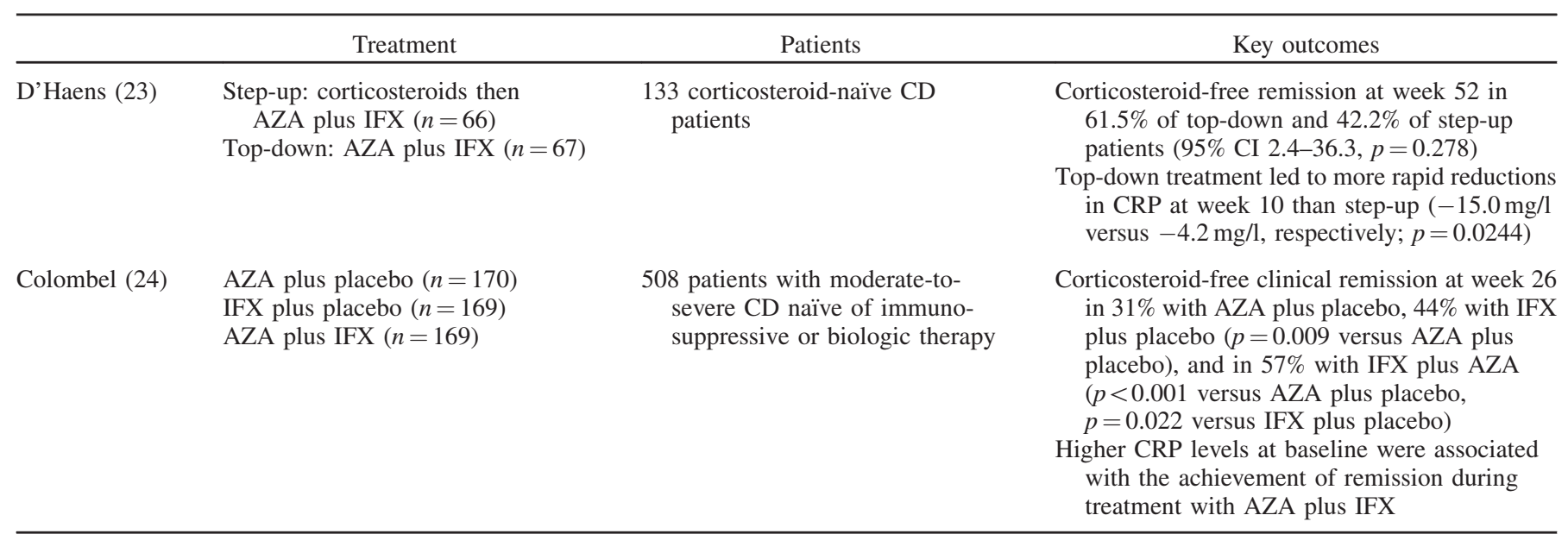

6-MP, 6-mercaptopurine; AZA, azathioprine; CRP, C-reactive protein; IFX, infliximab.

\section{Early intervention in psoriasis: crucial scientific questions}

\section{Designing the candidate patient population}

The candidate patient population for an early intervention trial in psoriasis should have rapidly progressing, aggressive skin disease.

\section{Natural history of psoriasis}

There are only limited data available on the natural history of psoriasis and on the factors predicting its prognosis. Although its course is continuous in the majority of patients with severe disease, psoriasis may show spontaneous exacerbations, improvements, and sometimes, persistent remission. The time interval between psoriasis episodes may vary from weeks to years. Studies have distinguished early onset psoriasis, defined as occurrence before the age of 40 years, and late onset psoriasis, occurring for the first time after age 40 years; patients with early onset psoriasis are more likely to have first-degree relatives affected, to express susceptibility alleles at the HLA locus, and to experience severe and recurrent disease $(108,109)$. However, the potential link between disease course and age of onset has not been confirmed by other studies $(110,111)$. No formal studies of the natural history of psoriasis are available. A questionnaire survey to more than 5000 patients in the USA found that psoriasis occurred in males and females with nearly equal frequency. The mean age at onset was 27.8 years with about $10 \%$ of patients having a disease onset before the age of 10 years, $35 \%$ before the age of 20 , and $58 \%$ before the age of 30 . About one-third of the patients indicated that one or more members of their families had psoriasis. About $40 \%$ of patients stated that psoriasis had disappeared completely with the duration of remission ranging from 1 to 54 years (112). A study on more than 700 patients from Sweden reported that in a period of 21 years, $71 \%$ of patients had persistent lesions, $16 \%$ had intermittent lesions, and $13 \%$ were disease free (113). In another study, persistent disease remission was observed in $17 \%$ of patients after 5 years, in $14 \%$ after 10 years and in 6\% after 20 years (114). Complete clearance without treatment during some part of the year was reported by about one-third of patients in a study conducted in the Indian subcontinent (115). In most studies, sunlight exposure, summer, or a warm temperate climate are associated with disease improvement. Factors exacerbating psoriasis include stressful life events, alcohol consumption, exposure to some drugs (e.g. lithium salts and interferons), and obesity.

\section{Treatment strategy and aims}

The aim of an early intervention study in psoriasis is proposed as follows: to obtain early, total or almost total clearance of psoriasis, with modification of the natural disease course and reduction of stigmatization.

The efficacy outcomes in an early intervention study may include the long-term remission of cutaneous signs (from a physician and patient perspective), improvements in HRQoL, and evaluation of systemic inflammation. Disease activity in psoriasis is typically measured using Psoriasis Area and Severity Index (PASI) responses. The PASI response appropriate for an early intervention study (up to and including PASI 100, or total clearance) needs to be defined. In most clinical studies, the outcome parameters have been PASI 75 (75\% reduction in PASI score versus baseline) and a subjective improvement in quality of life. On one hand, these goals are assessed in the short term, within 10-16 weeks of treatment initiation, corresponding to the induction phase of treatment. A PASI 50 response and a reduction from baseline in DLQI score of at least five have been proposed as minimum efficacy goals in daily practice, although PASI 50 may be considered insufficient by many patients $(93,97)$. On the other hand, therapeutic goals in the maintenance phase of treatment should be defined in terms of complete or nearly complete blanching, or minimal disease activity, regardless of baseline values. Thus, a static Physician's Global Assessment (PGA) of 0 or 1 , or an absolute PASI score $<5$, might be more suitable than a PASI 75 response (116), with the patient's HRQoL no longer be affected by the disease (e.g. a Dermatology Life Quality Index [DLQI] score of 0 or 1$)$.

In order to be able to alter the natural history of psoriasis by early intervention, a better understanding of the pathophysiology and natural course of the condition is required. This will enable more disease-specific intervention and treatment to be initiated earlier in the course of the condition. For example, it is not currently clear if systemic inflammation results from a spillover of inflammatory mediators from skin into the circulation, or just coincides with psoriasis due to an increased disposition for immune-mediated inflammation in general. If one assumes that inflammatory processes are continuing even in the absence of skin lesions, it may be difficult to classify the disease as in remission or inactive. In order to accurately quantify psoriasis disease activity and its relationship with systemic inflammation and immune activation, biological markers must be identified. Studies investigating biomarkers in PsA have identified C-reactive protein 


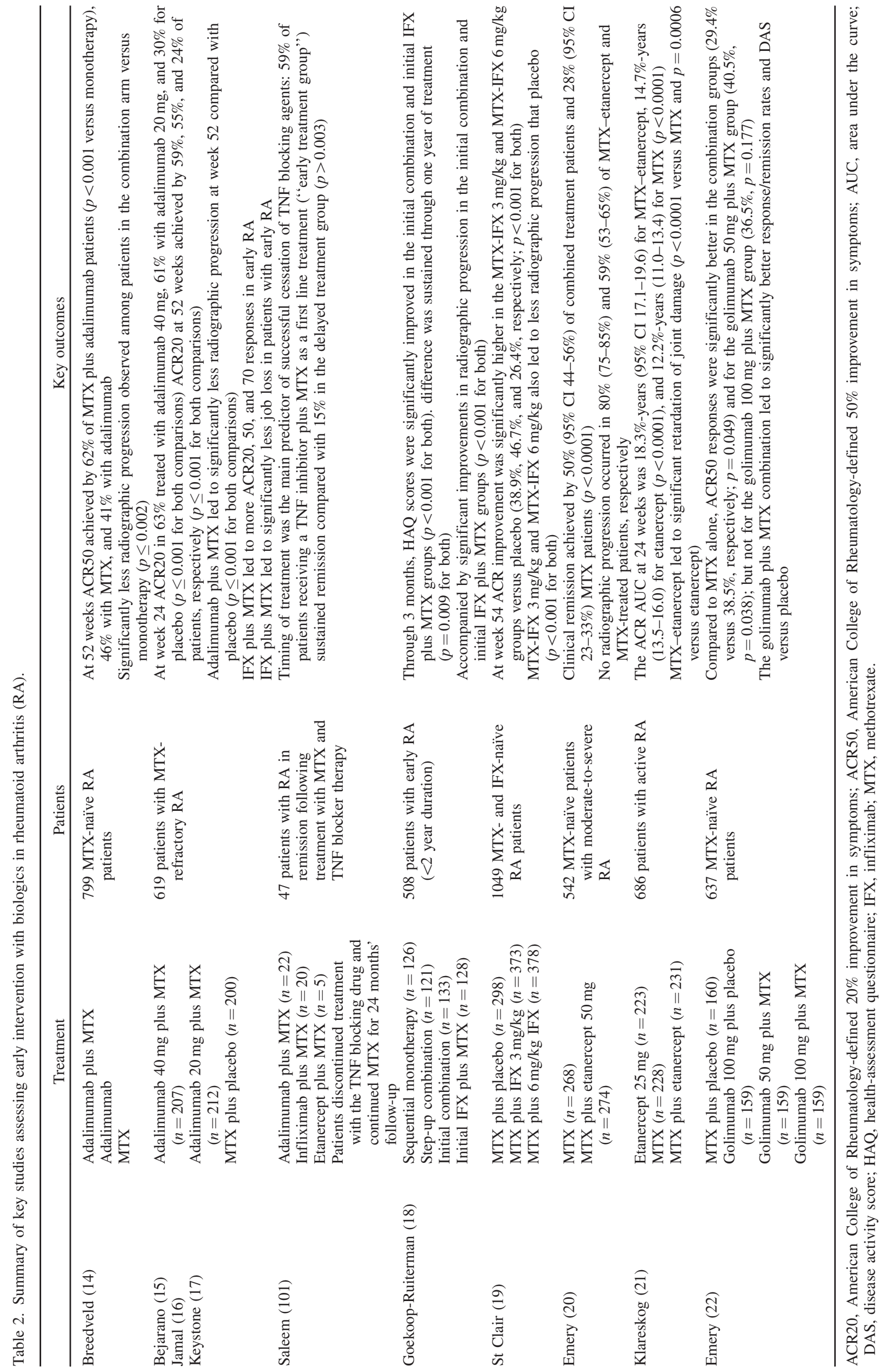


(CRP) and matrix metalloproteinase-3 (MMP-3) as promising candidate markers (117). Similarly, rates of corticosteroid-free clinical remission in $\mathrm{CD}$ patients receiving infliximab were greater among subgroups of patients with baseline CRP levels $\geq 0.8 \mathrm{mg} / \mathrm{dl}$ (24).

A second question in the design of an early intervention study is exactly how "early intervention" is to be defined. In RA, a qualitatively different effect with regard to joint damage has been observed if an intervention is used at one timepoint compared with another - the so-called "window of opportunity". In patients with RA, one manifestation of this is the ability to stop treatment without a disease flare. Clinical data have shown that flare is less likely if RA patients are treated early with an anti-TNF plus methotrexate, and if treatment takes place earlier after the development of symptoms (i.e., a median of 5.5 months) (101). It is, however, unclear if the timing of treatment similarly influences effects and outcomes in psoriasis.

Based on data obtained in studies of other IMIDs, there are three treatment paradigms that could be used in a psoriasis early intervention study: (1) patients are moved more rapidly along the existing treatment pathway, so systemic agents are used earlier; (2) patients with severe aggressive disease enter a disease management program including patient education, use of a systemic or a biologic agent with the goal to obtain complete or almost complete clearance; and (3) patients are treated with a biologic or systemic therapy at the first presentation of psoriasis and upon achieving remission are maintained on any conventional systemic therapy for the long term to maintain remission.

\section{Patient selection}

Patient selection protocols will be largely dependent on the definition of "early intervention"'. Early intervention could define a time window for the onset of systemic or biologic therapy of 612-24 months after first disease manifestation. However, patient selection implies a spectrum of choices and outcomes. For example, RA studies have shown that patients with early disease ( $<2$ years) exhibit better treatment responses than those with late disease (16). It is currently unclear if this would also apply in psoriasis, although it can be hypothesized that biologic or systemic treatment of psoriasis at disease onset might impact the inflammatory cascade and favorably affect the long-term course of psoriasis, and also halt social disconnection and stigmatization. This could potentially be determined at diagnosis using gene scans to identify those patients with high risk for developing severe psoriasis, PsA, and/or other IMIDs according to the presence of associated genes or single nucleotide polymorphisms (SNPs) at associated gene loci.

The clinical presentation of psoriasis (e.g. inflammatory psoriasis and widespread disease) could also guide the decision. For example, it has been shown that in patients with psoriasis the area of disease involvement during stable disease correlates with nail and joint involvement and the need for a second-line therapy (118). Plaque thickness has also been found to correlate with treatment response, where patients with thin plaques were more likely to report a complete clinical response following treatment with topical corticosteroids and phototherapy, but not systemic therapy (119).

Finally, there is the question of whether any types of psoriasis should be excluded from early intervention. Of course, only patients with moderate-to-severe psoriasis are eligible for treatment with systemic agents or biologics, making mild psoriasis (limited disease) patients ineligible for study. However, few patients develop severe psoriasis at or near disease onset. Despite this, a true early intervention approach requires treatment as rapidly as possible following the first identification of symptoms.
In an ongoing early intervention study in psoriatic arthritis, the maximum period between first symptoms of psoriatic arthritis and enrolment was defined as 2 years $(27,120)$.

In addition, there are several other forms of psoriasis that affect the HRQoL of patients to a similar degree. Although most research has been carried out on individuals with plaque-type psoriasis, other forms such as guttate, nail, or scalp psoriasis are equally as distressing and may be more or less responsive to treatment than plaque psoriasis.

\section{Endpoint selection}

Remission, or duration of off-treatment response, has been inconsistently defined in clinical studies of psoriasis therapies, and occasionally not defined at all. Definitions have included time until recurrence of $50 \%$ of baseline psoriasis, time until recurrence of $3 \%$ or more body surface area of psoriasis when the patient was “clear', and time until first worsening of existing lesions or appearance of a new lesion (121). A recent consensus publication has suggested the following definition for treatment success during the maintenance phase of treatment (i.e., the treatment period after the induction phase): "an improvement of PASI of $\geq 75 \%$ ( $\triangle \mathrm{PASI} \geq 75 \%$ ) as compared with disease severity at the time of treatment initiation" (122). According to another consensus, satisfactory therapeutic control of psoriasis should be defined in absolute, rather than relative terms: sustained complete or almost complete clearance $(\mathrm{PGA} \leq 1)$ or the minimal degree of involvement that can be controlled with topical treatment (PGA $\leq 2$, PASI $<5$ ) (116). Similarly, the definition of loss of adequate response, treatment failure, or relapse are variable between studies. Indeed, the REVEAL study, which compared the efficacy of adalimumab versus placebo, defined relapse as " $<$ PASI 50 relative to baseline with $\geq 6$-point increase in PASI from week 33' ' (123). Other definitions, such as a PGA score $>2$, should also be considered.

In $\mathrm{CD}$, the present therapeutic guidelines follow a sequential step-up approach that focuses on treating acute disease or "inducing clinical remission" and subsequently aims to "maintain clinical response", (124). In this regard, a common definition for psoriasis remission should be agreed among dermatologists. One possible definition could be the dermatologic element of the MDA (minimal disease activity) definition for psoriatic arthritis $(\mathrm{PASI} \leq 1$ and $\mathrm{BSA} \leq 3 \%)(125)$.

\section{Assessing the benefits of early intervention}

The aim of early intervention would be to improve the long-term course and prognosis of psoriasis. Currently, there are no predictors that would define the future course and severity of psoriasis at disease onset in the individual patient. Post-hoc subanalyses of clinical trials might provide some clues regarding a possible correlation between early treatment (shorter duration of (severe) disease and longer relapse times after adjusting for baseline PASI, arthritis, CRP, body weight, age, sex, and biologic used. Outcome measures or endpoints could include disease severity over time; HRQoL over time; duration of disease-free remissions after treatment breaks; treatment response after change to conventional therapy; laboratory indicators of systemic inflammation; retreatment or change to conventional therapy; and biomarkers or surrogate indicators of systemic inflammation. Early pilot studies have suggested that the treatment of psoriasis with systemic agents or anti-TNFs may improve biomarkers of cardiovascular risks $(126,127)$. Demonstration of a reduction in the incidence of cardiovascular or cerebrovascular events, metabolic syndrome, or PsA would represent a secondary gain, but the ultimate goal from a dermatological perspective, taking into account that no structural irreversible damage occurs in the skin, 
should be prolonged medication-free remission. The added value of early intervention may be difficult to define. It may require the comparison of large age-, sex-, and ethnically matched patient populations adjusted for additional risk factors such as smoking, body-mass index, waist circumference, hypertension, dyslipidaemia or diabetes, and the corresponding therapeutic interventions. Although the measures listed above provide evidence of the presence or absence of clinical disease, subclinical activity must also be considered. In RA, one study showed that when assessed using power Doppler and MRI, 19\% of patients thought to be in remission displayed deterioration in radiographic damage (105). Likewise, the inflammatory and epithelial genes that are associated with residual disease genomic profile - or genetic memory - in psoriasis may provide an estimation of subclinical disease activity and probability of relapse with or without treatment; while plaque thickness may provide a good measure of treatment response and the likelihood of a patient responding to treatment $(62,119)$.

Carefully designed study protocols are required to document the benefits of early intervention in psoriasis. (For example, achieving maintained complete remission or MDA for a given period of time might provide a rationale for biologic treatment discontinuation (128) if this reduces the likelihood of relapse requiring systemic treatment.) It should also be considered that the required observation periods for such studies in psoriasis might exceed those that can be covered by clinical trials and, as such, necessitate the transfer of patients from early intervention studies into long-term observational pharmacovigilance registries, e.g. BADBIR in the UK, Psocare in Italy, and PsoBest in Germany. Indeed, these registries may themselves provide data on the effect of intervention on the course of disease.

\section{Conclusions}

Psoriasis is an inflammatory disease that not only affects the skin but may also act systemically to influence serious comorbidities. Many agents currently used early in treating psoriasis target the development of skin lesions. However, disease control and long-term outcomes of psoriasis as a systemic disease are key treatment goals in psoriasis. The efficacy of early intervention has been demonstrated in many studies of patients with RA and CD. However, there is a need to reach consensus on a number of definitions before such studies could be carried out in psoriasis. It is important to accumulate more data on the natural history of psoriasis, to have in place a universally accepted definition of disease activity in psoriasis and to have identified biomarkers to quantify changes in disease activity and subclinical inflammation during and after treatment. An early intervention study must also identify the most appropriate way of using early intervention, the patients that should be enrolled in the study, and the treatments that should be included. Resolving these issues and initiating early intervention studies in psoriasis is essential to identify new treatment paradigms with the potential to change the course of the disease and improve patient outcomes in the long term.

\section{Acknowledgements}

The authors thank S. McGrath and C. Incles of IntraMed Europe for writing support and editorial assistance.

\section{Declaration of interest}

The authors report no conflicts of interest. The authors alone are responsible for the content and writing of this article. Funding sources: Development of this article was supported by Janssen Pharmaceutica NV.

\section{Interest disclosures}

G. G. has been a consultant, investigator, and/or speaker for Abbot, GSK, Janssen, Merck-Serono, MSD, Novartis; C. G. has been a consultant, investigator and/or speaker for Abbott, Janssen, Leo, MSD, Novartis, Pfizer; J. K. has been a consultant, investigator, and/or speaker for Centocor, Janssen, Lilly, Merck-Serono, Pfizer; F. N. has been a consultant, investigator and/or speaker for Celgene, Basilea, Janssen, Novartis, Pfizer; J. F. N. has been a consultant, investigator and/or speaker for Janssen; J. P. has been a consultant, investigator, and/or speaker for Abbott, Biogen-Idec, Centocor, Essex pharma, Galderma, Janssen, MerkSerono, Novartis, Pfitzer, Wyeth; L. P. has been a consultant, investigator, and/or speaker for Abbott, Amgen, Celgene, Janssen, Leo, Merck-Serono, Pfizer; M. S. has been a consultant, investigator and/or speaker for Janssen, Pfizer; P. v. D. K. has been a consultant, investigator, and/or speaker for Abbott, Actelion, Almirall, Celgene, Centocor, Galderma, Janssen, Leo Pharma, Merck-Serono, Novartis, Philips Lighting, Pfizer, Schering Plough, Soffinova, UCB, Wyeth; M. A. has been a consultant, investigator, and/or speaker for Abbott, Janssen, MSD; P. E. has been a consultant, investigator, and/or speaker for Abbott, Janssen, Merck, Novartis, Pfizer; C. P. has been a consultant, investigator, and/or speaker for Abbott, Amgen, Astellas, Basilea, Celgene, Janssen, Novartis, Pierre Fabre.

\section{References}

1. Langley RG, Krueger GG, Griffiths CEM. Psoriasis: epidemiology, clinical features, and quality of life. Ann Rheum Dis. 2005;64: ii18-23.

2. Naldi L. Epidemiology of psoriasis. Curr Drug Targets Inflamm Allergy. 2004;3:121-8.

3. Meyer N, Paul C, Feneron D, et al. Psoriasis: an epidemiological evaluation of disease burden in 590 patients. J Eur Acad Dermatol Venereol. 2010;24:1075-82.

4. Kimball AB, Gieler U, Linder D, et al. Psoriasis: is the impairment to a patient's life cumulative? J Eur Acad Dermatol Venereol. 2010; 24:989-1004.

5. Horn EJ, Fox KM, Patel V, et al. Association of patient-reported psoriasis severity with income and employment. J Am Acad Dermatol. 2007;57:963-71.

6. Gelfand JM, Feldman SR, Stern RS, et al. Determinants of quality of life in patients with psoriasis: a study from the US population. J Am Acad Dermatol. 2004;51:704-8.

7. Finzi A, Colombo D, Caputo A, et al. Psychological distress and coping strategies in patients with psoriasis: the PSYCHAE study. J Eur Acad Dermatol Venereol. 2007;21:1161-9.

8. Kleyn CE, McKie S, Ross AR, et al. Diminished neural and cognitive responses to facial expressions of disgust in patients with psoriasis: a functional magnetic resonance imaging study. J Invest Dermatol. 2009;129:2613-9.

9. Armstrong AW, Harskamp CT, Armstrong EJ. Psoriasis and metabolic syndrome: a systematic review and meta-analysis of observational studies. J Am Acad Dermatol. 2013;68:654-62.

10. Prey S, Paul C, Bronsard V, et al. Cardiovascular risk factors in patients with plaque psoriasis: a systematic review of epidemiological studies. J Eur Acad Dermatol Venereol. 2010;24:23-30.

11. Samarasekera EJ, Neilson JM, Warren RB, et al. Incidence of cardiovascular disease in individuals with psoriasis: a systematic review and meta-analysis. J Invest Dermatol. 2013;133:2340-6.

12. Nestle FO, Kaplan DH, Barker J. Psoriasis. N Engl J Med. 2009;361: 496-509.

13. Mease PJ, Gladman DD, Papp KA, et al. Prevalence of rheumatologist-diagnosed psoriatic arthritis in patients with psoriasis in European/North American dermatology clinics. J Am Acad Dermatol. 2013;69:729-35.

14. Breedveld FC, Weisman MH, Kavanaugh AF, et al. The PREMIER study: a multicenter, randomized, double-blind clinical trial of combination therapy with adalimumab plus methotrexate versus methotrexate alone or adalimumab alone in patients with early, aggressive rheumatoid arthritis who had not had previous methotrexate treatment. Arthritis Rheum. 2006;54:26-37.

15. Bejarano V, Quinn M, Conaghan PG, et al. Effect of the early use of the anti-tumor necrosis factor adalimumab on the prevention of job loss in patients with early rheumatoid arthritis. Arthritis Rheum. 2008;59:1467-74. 
16. Jamal S, Patra K, Keystone EC. Adalimumab response in patients with early versus established rheumatoid arthritis: DE019 randomized controlled trial subanalysis. Clin Rheumatol. 2009;28:413-9.

17. Keystone EC, Kavanaugh AF, Sharp JT, et al. Radiographic, clinical, and functional outcomes of treatment with adalimumab (a human anti-tumor necrosis factor monoclonal antibody) in patients with active rheumatoid arthritis receiving concomitant methotrexate therapy: a randomized, placebo-controlled, 52-week trial. Arthritis Rheum. 2004;50:1400-11.

18. Goekoop-Ruiterman YP, de Vries-Bouwstra JK, Allaart CF, et al. Clinical and radiographic outcomes of four different treatment strategies in patients with early rheumatoid arthritis (the BeSt study): a randomized, controlled trial. Arthritis Rheum. 2005;52: 3381-90.

19. St Clair EW, van der Heijde DM, Smolen JS, et al. Combination of infliximab and methotrexate therapy for early rheumatoid arthritis: a randomized, controlled trial. Arthritis Rheum. 2004;50:3432-43.

20. Emery P, Breedveld FC, Hall S, et al. Comparison of methotrexate monotherapy with a combination of methotrexate and etanercept in active, early, moderate to severe rheumatoid arthritis (COMET): a randomised, double-blind, parallel treatment trial. Lancet. 2008;372: 375-82.

21. Klareskog L, van der Heijde D, de Jager JP, et al. Therapeutic effect of the combination of etanercept and methotrexate compared with each treatment alone in patients with rheumatoid arthritis: doubleblind randomised controlled trial. Lancet. 2004:363:675-81.

22. Emery P, Fleischmann RM, Moreland LW, et al. Golimumab, a human anti-tumor necrosis factor alpha monoclonal antibody, injected subcutaneously every four weeks in methotrexate-naive patients with active rheumatoid arthritis: twenty-four-week results of a phase III, multicenter, randomized, double-blind, placebocontrolled study of golimumab before methotrexate as first-line therapy for early-onset rheumatoid arthritis. Arthritis Rheum. 2009; 60:2272-83.

23. D'Haens G, Baert F, Van AG, et al. Early combined immunosuppression or conventional management in patients with newly diagnosed Crohn's disease: an open randomised trial. Lancet. 2008;371:660-7.

24. Colombel JF, Sandborn WJ, Reinisch W, et al. Infliximab, azathioprine, or combination therapy for Crohn's disease. N Engl J Med. 2010;362:1383-95.

25. Lemann M, Mary JY, Duclos B, et al. Infliximab plus azathioprine for steroid-dependent Crohn's disease patients: a randomized placebo-controlled trial. Gastroenterology. 2006;130:1054-61.

26. Targan SR, Hanauer SB, van Deventer SJ, et al. A short-term study of chimeric monoclonal antibody cA2 to tumor necrosis factor alpha for Crohn's disease. Crohn's Disease cA2 Study Group. N Engl J Med. 1997;337:1029-35.

27. Saraceno R, Griffiths CE. A European perspective on the challenges of managing psoriasis. J Am Acad Dermatol. 2006;54: S81-4.

28. Gardinal I, Ammoury A, Paul C. Moderate to severe psoriasis: from topical to biological treatment. J Eur Acad Dermatol Venereol. 2009;23:1324-6.

29. Maza A, Richard MA, Aubin F, et al. Significant delay in the introduction of systemic treatment of moderate to severe psoriasis: a prospective multicentre observational study in outpatients from hospital dermatology departments in France. Br J Dermatol. 2012; 167:643-8.

30. Farber EM, Nall ML, Watson W. Natural history of psoriasis in 61 twin pairs. Arch Dermatol. 1974;109:207-11.

31. Bowcock AM, Krueger JG. Getting under the skin: the immunogenetics of psoriasis. Nat Rev Immunol. 2005;5:699-711.

32. Tsoi LC, Spain SL, Knight J, et al. Identification of 15 new psoriasis susceptibility loci highlights the role of innate immunity. Nat Genet. 2012;44:1341-8.

33. Capon F, Di Meglio P, Szaub J, et al. Sequence variants in the genes for the interleukin-23 receptor (IL23R) and its ligand (IL12B) confer protection against psoriasis. Hum Genet. 2007;122:201-6.

34. Cargill M, Schrodi SJ, Chang M, et al. A large-scale genetic association study confirms IL12B and leads to the identification of IL23R as psoriasis-risk genes. Am J Hum Genet. 2007;80:273-90.

35. Li Y, Liao W, Chang M, et al. Further genetic evidence for three psoriasis-risk genes: ADAM33, CDKAL1, and PTPN22. J Invest Dermatol. 2009;129:629-34.
36. Nair RP, Duffin KC, Helms C, et al. Genome-wide scan reveals association of psoriasis with IL-23 and NF-kappaB pathways. Nat Genet. 2009;41:199-204.

37. Capon F, Bijlmakers MJ, Wolf N, et al. Identification of ZNF313/ RNF114 as a novel psoriasis susceptibility gene. Hum Mol Genet. 2008; 17:1938-45.

38. Strange A, Capon F, Spencer CC, et al. A genome-wide association study identifies new psoriasis susceptibility loci and an interaction between HLA-C and ERAP1. Nat Genet. 2010;42:985-90.

39. Stuart PE, Nair RP, Ellinghaus E, et al. Genome-wide association analysis identifies three psoriasis susceptibility loci. Nat Genet. 2010;42:1000-4

40. Ellinghaus E, Ellinghaus D, Stuart PE, et al. Genome-wide association study identifies a psoriasis susceptibility locus at TRAF3IP2. Nat Genet. 2010;42:991-5.

41. Bijlmakers MJ, Kanneganti SK, Barker JN, et al. Functional analysis of the RNF114 psoriasis susceptibility gene implicates innate immune responses to double-stranded RNA in disease pathogenesis. Hum Mol Genet. 2011;20:3129-37.

42. Bowes J, Eyre S, Flynn E, et al. Evidence to support IL-13 as a risk locus for psoriatic arthritis but not psoriasis vulgaris. Ann Rheum Dis. 2011;70:1016-9.

43. Bowes J, Flynn E, Ho P, et al. Variants in linkage disequilibrium with the late cornified envelope gene cluster deletion are associated with susceptibility to psoriatic arthritis. Ann Rheum Dis. 2010;69: 2199-203.

44. Chang M, Li Y, Yan C, et al. Variants in the $5 \mathrm{q} 31$ cytokine gene cluster are associated with psoriasis. Genes Immun. 2008;9:176-81.

45. de Cid R, Riveira-Munoz E, Zeeuwen PL, et al. Deletion of the late cornified envelope LCE3B and LCE3C genes as a susceptibility factor for psoriasis. Nat Genet. 2009;41:211-5.

46. Duffin KC, Freeny IC, Schrodi SJ, et al. Association between IL13 polymorphisms and psoriatic arthritis is modified by smoking. J Invest Dermatol. 2009;129:2777-83.

47. Duffin KC, Woodcock J, Krueger GG. Genetic variations associated with psoriasis and psoriatic arthritis found by genome-wide association. Dermatol Ther. 2010;23:101-13.

48. Huffmeier U, Estivill X, Riveira-Munoz E, et al. Deletion of LCE3C and LCE3B genes at PSORS4 does not contribute to susceptibility to psoriatic arthritis in German patients. Ann Rheum Dis. 2010;69: 876-8.

49. Huffmeier U, Lascorz J, Bohm B, et al. Genetic variants of the IL-23R pathway: association with psoriatic arthritis and psoriasis vulgaris, but no specific risk factor for arthritis. J Invest Dermatol. 2009;129:355-8.

50. Huffmeier $\mathrm{U}$, Uebe $\mathrm{S}$, Ekici $\mathrm{AB}$, et al. Common variants at TRAF3IP2 are associated with susceptibility to psoriatic arthritis and psoriasis. Nat Genet. 2010;42:996-9.

51. Liu Y, Helms C, Liao W, et al. A genome-wide association study of psoriasis and psoriatic arthritis identifies new disease loci. PLoS Genet. 2008;4:e1000041.

52. Nair RP, Ruether A, Stuart PE, et al. Polymorphisms of the IL12B and IL23R genes are associated with psoriasis. J Invest Dermatol. 2008;128:1653-61.

53. Quaranta M, Burden AD, Griffiths CE, et al. Differential contribution of CDKAL1 variants to psoriasis, Crohn's disease and type II diabetes. Genes Immun. 2009;10:654-8.

54. Smith RL, Warren RB, Eyre S, et al. Polymorphisms in the IL-12beta and IL-23R genes are associated with psoriasis of early onset in a UK cohort. J Invest Dermatol. 2008;128:1325-7.

55. Sun LD, Cheng H, Wang ZX, et al. Association analyses identify six new psoriasis susceptibility loci in the Chinese population. Nat Genet. 2010;42:1005-9.

56. $\mathrm{Xu} \mathrm{L}, \mathrm{Li}$ Y, Zhang X, et al. Deletion of LCE3C and LCE3B genes is associated with psoriasis in a northern Chinese population. $\mathrm{Br} \mathrm{J}$ Dermatol. 2011;165:882-7.

57. Zhang XJ, Huang W, Yang S, et al. Psoriasis genome-wide association study identifies susceptibility variants within LCE gene cluster at 1q21. Nat Genet. 2009;41:205-10.

58. Zheng HF, Zuo XB, Lu WS, et al. Variants in MHC, LCE and IL12B have epistatic effects on psoriasis risk in Chinese population. J Dermatol Sci. 2011;61:124-8.

59. Wolf N, Quaranta M, Prescott NJ, et al. Psoriasis is associated with pleiotropic susceptibility loci identified in type II diabetes and Crohn disease. J Med Genet. 2008;45:114-6. 
60. Bergboer JG, Tjabringa GS, Kamsteeg M, et al. Psoriasis risk genes of the late cornified envelope-3 group are distinctly expressed compared with genes of other LCE groups. Am J Pathol. 2011;178: 1470-7.

61. Suarez-Farinas M, Fuentes-Duculan J, Lowes MA, et al. Resolved psoriasis lesions retain expression of a subset of disease-related genes. J Invest Dermatol. 2011;131:391-400.

62. Clark RA. Gone but not forgotten: lesional memory in psoriatic skin. J Invest Dermatol. 2011;131:283-5.

63. Eyre RW, Krueger GG. Response to injury of skin involved and uninvolved with psoriasis, and its relation to disease activity: Koebner and 'reverse' Koebner reactions. Br J Dermatol. 1982;106: 153-9.

64. Gudjonsson JE, Thorarinsson AM, Sigurgeirsson B, et al. Streptococcal throat infections and exacerbation of chronic plaque psoriasis: a prospective study. Br J Dermatol. 2003;149:530-4.

65. Nickoloff BJ, Nestle FO. Recent insights into the immunopathogenesis of psoriasis provide new therapeutic opportunities. J Clin Invest. 2004;113:1664-75.

66. Richards HL, Ray DW, Kirby B, et al. Response of the hypothalamic-pituitary-adrenal axis to psychological stress in patients with psoriasis. Br J Dermatol. 2005;153:1114-20.

67. Telfer NR, Chalmers RJ, Whale K, et al. The role of streptococcal infection in the initiation of guttate psoriasis. Arch Dermatol. 1992; 128:39-42.

68. Tsankov N, Angelova I, Kazandjieva J. Drug-induced psoriasis. Recognition and management. Am J Clin Dermatol. 2000;1:159-65.

69. Lande R, Gregorio J, Facchinetti V, et al. Plasmacytoid dendritic cells sense self-DNA coupled with antimicrobial peptide. Nature. 2007;449:564-9.

70. Charles J, Chaperot L, Salameire D, et al. Plasmacytoid dendritic cells and dermatological disorders: focus on their role in autoimmunity and cancer. Eur J Dermatol. 2010;20:16-23.

71. Nestle FO, Conrad C, Tun-Kyi A, et al. Plasmacytoid predendritic cells initiate psoriasis through interferon-alpha production. J Exp Med. 2005;202:135-43.

72. Mrowietz U, Elder JT, Barker J. The importance of disease associations and concomitant therapy for the long-term management of psoriasis patients. Arch Dermatol Res. 2006;298:309-19.

73. Gottlieb AB, Chao C, Dann F. Psoriasis comorbidities. J Dermatolog Treat. 2008;19:5-21.

74. Prey S, Paul C, Bronsard V, et al. Assessment of risk of psoriatic arthritis in patients with plaque psoriasis: a systematic review of the literature. J Eur Acad Dermatol Venereol. 2010;24:31-5.

75. Yates VM, Watkinson G, Kelman A. Further evidence for an association between psoriasis, Crohn's disease and ulcerative colitis. Br J Dermatol. 1982;106:323-30.

76. Rahman P, Inman RD, Maksymowych WP, et al. Association of interleukin 23 receptor variants with psoriatic arthritis. J Rheumatol. 2009;36:137-40.

77. Mallbris L, Akre O, Granath F, et al. Increased risk for cardiovascular mortality in psoriasis inpatients but not in outpatients. Eur J Epidemiol. 2004;19:225-30.

78. Gelfand JM, Neimann AL, Shin DB, et al. Risk of myocardial infarction in patients with psoriasis. JAMA. 2006;296:1735-41.

79. Gelfand JM, Dommasch ED, Shin DB, et al. The risk of stroke in patients with psoriasis. J Invest Dermatol. 2009;129:2411-8.

80. Gelfand JM, Azfar RS, Mehta NN. Psoriasis and cardiovascular risk: strength in numbers. J Invest Dermatol. 2010;130:919-22.

81. Boehncke WH, Boehncke S, Schon MP. Managing comorbid disease in patients with psoriasis. BMJ. 2010;340:b5666.

82. Gisondi P, Farina S, Giordano MV, et al. Usefulness of the Framingham risk score in patients with chronic psoriasis. Am J Cardiol. 2010;106:1754-7.

83. Gisondi P, Dalle Vedove C, Girolomoni G. Patients with psoriasis have a higher prevalence of parental cardiovascular disease. Dermatology. 2011;222:330-5.

84. Gisondi P, Fantin F, Del GM, et al. Chronic plaque psoriasis is associated with increased arterial stiffness. Dermatology. 2009;218: $110-3$.

85. Prodanovich S, Kirsner RS, Kravetz JD, et al. Association of psoriasis with coronary artery, cerebrovascular, and peripheral vascular diseases and mortality. Arch Dermatol. 2009;145:700-3.

86. Stern RS, Huibregtse A. Very severe psoriasis is associated with increased noncardiovascular mortality but not with increased cardiovascular risk. J Invest Dermatol. 2011;131:1159-66.
87. Gelfand JM, Troxel AB, Lewis JD, et al. The risk of mortality in patients with psoriasis: results from a population-based study. Arch Dermatol. 2007;143:1493-9.

88. Suarez-Farinas M, Li K, Fuentes-Duculan J, et al. Expanding the psoriasis disease profile: interrogation of the skin and serum of patients with moderate-to-severe psoriasis. J Invest Dermatol. 2012;132:2552-64.

89. Linder MD, Kimball AB, eds. Dermatological Diseases and Cumulative Life Course Impairment. Basel: S. Karger AG, 2013.

90. Bostoen J, Bracke S, De Keyser S, et al. An educational programme for patients with psoriasis and atopic dermatitis: a prospective randomized controlled trial. Br J Dermatol. 2012;167:1025-31.

91. Bosello S, Santoliquido A, Zoli A, et al. TNF-alpha blockade induces a reversible but transient effect on endothelial dysfunction in patients with long-standing severe rheumatoid arthritis. Clin Rheumatol. 2008;27:833-9.

92. Dixon WG, Watson KD, Lunt M, et al. Reduction in the incidence of myocardial infarction in patients with rheumatoid arthritis who respond to anti-tumor necrosis factor alpha therapy: results from the British Society for Rheumatology Biologics Register. Arthritis Rheum. 2007;56:2905-12.

93. Pathirana D, Ormerod AD, Saiag P, et al. European S3-guidelines on the systemic treatment of psoriasis vulgaris. J Eur Acad Dermatol Venereol. 2009;23:1-70.

94. Pariente B, Cosnes J, Danese S, et al. Development of the Crohn's disease digestive damage score, the Lemann score. Inflamm Bowel Dis. 2011;17:1415-22.

95. Dignass A, Van Assche G, Lindsay JO, et al. The second European evidence-based consensus on the diagnosis and management of Crohn's disease: current management. J Crohns Colitis. 2010;4: $28-62$.

96. Froslie KF, Jahnsen J, Moum BA, et al. Mucosal healing in inflammatory bowel disease: results from a Norwegian populationbased cohort. Gastroenterology. 2007;133:412-22.

97. Rutgeerts P, Diamond RH, Bala M, et al. Scheduled maintenance treatment with infliximab is superior to episodic treatment for the healing of mucosal ulceration associated with Crohn's disease. Gastrointest Endosc. 2006;63:433-42.

98. Schnitzler F, Fidder H, Ferrante M, et al. Mucosal healing predicts long-term outcome of maintenance therapy with infliximab in Crohn's disease. Inflamm Bowel Dis. 2009;15:1295-301.

99. Baert F, Moortgat L, Van AG, et al. Mucosal healing predicts sustained clinical remission in patients with early-stage Crohn's disease. Gastroenterology. 2010;138:463-8.

100. Klarenbeek NB, Allaart CF, Kerstens PJ, et al. The best story: on strategy trials in rheumatoid arthritis. Curr Opin Rheumatol. 2009; 21:291-8.

101. Saleem B, Keen H, Goeb V, et al. Patients with RA in remission on TNF blockers: when and in whom can TNF blocker therapy be stopped? Ann Rheum Dis. 2010;69:1636-42.

102. Klarenbeek NB, Guler-Yuksel M, van der Kooij SM, et al. The impact of four dynamic, goal-steered treatment strategies on the 5 -year outcomes of rheumatoid arthritis patients in the best study. Ann Rheum Dis. 2011;70:1039-46.

103. Brown AK, Quinn MA, Karim Z, et al. Presence of significant synovitis in rheumatoid arthritis patients with disease-modifying antirheumatic drug-induced clinical remission: evidence from an imaging study may explain structural progression. Arthritis Rheum. 2006;54:3761-73.

104. Bejarano V, Conaghan PG, Quinn MA, et al. Benefits 8 years after a remission induction regime with an infliximab and methotrexate combination in early rheumatoid arthritis. Rheumatology (Oxford). 2010;49:1971-4.

105. Brown AK, Conaghan PG, Karim Z, et al. An explanation for the apparent dissociation between clinical remission and continued structural deterioration in rheumatoid arthritis. Arthritis Rheum. 2008;58:2958-67.

106. Lagana B, Picchianti DA, Ferlito C, et al. Imaging progression despite clinical remission in early rheumatoid arthritis patients after etanercept interruption. Int J Immunopathol Pharmacol. 2009;22: 447-54.

107. Barkham N, Keen HI, Coates LC, et al. Clinical and imaging efficacy of infliximab in HLA-B27-positive patients with magnetic resonance imaging-determined early sacroiliitis. Arthritis Rheum. 2009;60:946-54. 
108. Henseler T, Christophers E. Psoriasis of early and late onset: characterization of two types of psoriasis vulgaris. J Am Acad Dermatol. 1985;13:450-6.

109. Ferrandiz C, Pujol RM, Garcia-Patos V, et al. Psoriasis of early and late onset: a clinical and epidemiologic study from Spain. J Am Acad Dermatol. 2002;46:867-73.

110. Swanbeck G, Inerot A, Martinsson T, et al. Age at onset and different types of psoriasis. Br J Dermatol. 1995;133:768-73.

111. de Jager ME, de Jong EM, Meeuwis KA, et al. No evidence found that childhood onset of psoriasis influences disease severity, future body mass index or type of treatments used. J Eur Acad Dermatol Venereol. 2010;24:1333-9.

112. Farber EM, Nall ML. The natural history of psoriasis in 5,600 patients. Dermatologica. 1974;148:1-18.

113. Romanus T. Psoriasis from a prognostic and hereditary point of view. Dissertation, Uppsala, 1945.

114. Lomholt G. Psoriasis: Prevalence, Spontaneous Course and Genetics. A Census Study of Skin Diseases on the Faroe Islands. Copenhagen: G.E.C. Gad, 1963.

115. Kaur I, Handa S, Kumar B. Natural history of psoriasis: a study from the Indian subcontinent. J Dermatol. 1997;24:230-4.

116. Puig L, Bordas X, Carrascosa JM, et al. [Consensus document on the evaluation and treatment of moderate-to-severe psoriasis. Spanish psoriasis group of the Spanish Academy of Dermatology and Venereology]. Actas Dermosifiliogr. 2009;100:277-86.

117. Chandran V, Gladman DD. Update on biomarkers in psoriatic arthritis. Curr Rheumatol Rep. 2010;12:288-94.

118. Osborne JE, Hutchinson PE. Demographic and clinical correlates of extent of psoriasis during stable disease and during flares in chronic plaque psoriasis. Br J Dermatol. 2008;158:721-6.

119. Rakkhit T, Panko JM, Christensen TE, et al. Plaque thickness and morphology in psoriasis vulgaris associated with therapeutic response. Br J Dermatol. 2009;160:1083-9.
120. Coates LC, Navarro-Coy N, Brown SR, et al. The TICOPA protocol (TIght COntrol of Psoriatic Arthritis): a randomised controlled trial to compare intensive management versus standard care in early psoriatic arthritis. BMC Musculoskelet Disord. 2013; $14: 101$.

121. Langley RG, Gordon KB. Duration of remission of biologic agents for chronic plaque psoriasis. J Drugs Dermatol. 2007;6: 1205-12.

122. Mrowietz U, Kragballe K, Reich K, et al. Definition of treatment goals for moderate to severe psoriasis: a European consensus. Arch Dermatol Res. 2011;303:1-10.

123. Menter A, Tyring SK, Gordon K, et al. Adalimumab therapy for moderate to severe psoriasis: a randomized, controlled phase III trial. J Am Acad Dermatol. 2008;58:106-15.

124. Lin MV, Blonski W, Lichtenstein GR. What is the optimal therapy for Crohn's disease: step-up or top-down? Expert Rev Gastroenterol Hepatol. 2010;4:167-80.

125. Coates LC, Fransen J, Helliwell PS. Defining minimal disease activity in psoriatic arthritis: a proposed objective target for treatment. Ann Rheum Dis. 2010;69:48-53.

126. Boehncke S, Salgo R, Garbaraviciene J, et al. Effective continuous systemic therapy of severe plaque-type psoriasis is accompanied by amelioration of biomarkers of cardiovascular risk: results of a prospective longitudinal observational study. J Eur Acad Dermatol Venereol. 2011;25:1187-93.

127. Boehncke S, Fichtlscherer S, Salgo R, et al. Systemic therapy of plaque-type psoriasis ameliorates endothelial cell function: results of a prospective longitudinal pilot trial. Arch Dermatol Res. 2011; 303:381-8.

128. Chimenti MS, Graceffa D, Perricone R. Anti-TNFalpha discontinuation in rheumatoid and psoriatic arthritis: is it possible after disease remission? Autoimmun Rev. 2011;10: 636-40. 